\title{
Por una educación intercultural.
}

\author{
Emigrantes.
}

JOSÉ DOMINGUEZ

Maestro de Almería que ha trabajado con minorias étnicas y emigrantes.

Ante el auge de actitudes racistas y/o xenofobas y en una sociedad cada vez más multiétnica y multicultural, el Sistema Educativo debe contribuir con decisión, tanto a atender adecuadamente a la población inmigrante en edad escolar; afrontando los nuevos retos organizativos y pedagógicos que ello implica, como contribuir a la formación de niños y niñas procurando que lejos de que aniden prejuicios racistas $\mathrm{e}$ interancia, crezcan valores de solidaridad, aprecio, respeto a culturas diferentes.

Hoy por hoy ambos objetivos están desatendidos por el Sistema Educativo, si bien hay excepciones debidas fundamentalmente al voluntarismo de algunos maestros y maestras.

La obligación de los estados de atender adecuadamente a la población infantil inmigrante viene avalada por numerosas resoluciones de organismos internacionales (ONU y Parlamento Europeo fundamentalmente), si bien reconocen los mismos organismos el incumplimiento sistemático de sus propias decisiones total o parcialmente por la mayoría de los países.

Quizás el documento más significativo haya sido la directiva 
comunitaria 486 de 25 de julio de 1.977 sobre escolarización de hijos e hijas de inmigrantes. Esta directiva, que vincula a los países miembros debía estar aplicándose al 2 de agosto de 1.981. Un informe del Parlamento Europeo de 3 de enero de 1.989 reconoce que sólo los Países Bajos y en menor medida R.F.Alemana habían adoptado medidas significativas contenidas en la mencionada Directiva.

Cabe destacar por el valor de las 77 "Recomendaciones" que acogen sus conclusiones, el "Informe Ford" del Parlamento Europeo presentado en el verano de 1.990 (1).

A pesar de la evidente necesidad de actuación y de las recomendaciones institucionales, y en lo que al Estado Español se refiere, las administraciones educativas (MEC y Comunidades Autónomas) no han tomado ninguna medida seria en relación al tema, si bien empieza a aparecer algún material. Esta parcela se le está encomendando a los Programas de Educación Compensatoria sin que se conozca un plan de actuación específico. Entre las medidas que deberían adoptarse cabría citar las siguientes:

1. La inclusión en los Planes de Formación inicial del profesorado asignaturas o materias que faciliten fundamentos teóricos de la interculturalidad, así como estrategias y recursos para la prevención del racismo y la xenofobia.

2. Realizar una oferta de actividades de perfeccionamiento al profesorado en ejercicio que facilite, tanto la adopción de actitudes positivas en relación a la diversidad cultural como recursos educativos para una eficiente educación antirracista.

3. Necesidad de personal sensibilizado y preparado profesionalmente (asesorias, equipos de apoyo externo, ...) que puedan ayudar a los centros que escolarizan inmigrantes mediante la sensibilización, apoyo organizativo, adaptación curricular en su caso, etc.

Atender progresivamente estas tareas proporcionarán un profe- 
sorado más sensibilizado, con mayor preparación y con mejores recursos para enfrentarse a estas situaciones novedosas.

(1) Transcribimos algunas recomendaciones relacionadas con el hecho educativo:

* 69. ...es vital que los niños no se impregnen en la escuela de actitudes racistas, sino que por el contrario aprendan los beneficios que se pueden derivar de la vida en una sociedad multicultural.

* 71. Que los estados miembros introduzcan la educación contra el racismo en el currículum de sus escuelas primarias como materia obligatoria.

* 72. Que los estados miembros adopten políticas que permitan que los hijos de población mayoritaria y de las minorías étnicas sean educados juntos.

* 73. Que los Estados miembros intensifiquen la participación del Sistema Educativo en la lucha contra el racismo, el antisemitismo y la xenofobia, mediante la enseñanza en los centros escolares de los Derechos Humanos y de la Historia, y mediante la formación del profesorado y la investigación universitaria.

\section{BIBLIOGRAFía}

* Informe Ford sobre el racismo en Europa. INSS. 1991

* Educación Intercultural: la Europa sin fronteras. P.FERMOSO. Ed.Narcea

* Inmigración, pluralismo y tolerancia. L.ABAD, A.CUCO, A.IZQUIERDO. Ed.Popular

* Educación multicultural y multilingüe. TORSTEN HUSEN/ SUSAN OPPER. Ed. Narcea 1984 